\title{
Vitamin D status among preterm and full-term infants at birth
}

\author{
Heather H. Burris ${ }^{1-3}$, Linda J. Van Marter ${ }^{1,3,4}$, Thomas F. McElrath ${ }^{1,5}$, Patrik Tabatabai ${ }^{6}$, Augusto A. Litonjua ${ }^{1,7,8}$, Scott T. Weiss ${ }^{1,7,8}$ \\ and Helen Christou ${ }^{1,3,4}$
}

BACKGROUND: Risk factors for maternal vitamin D deficiency and preterm birth overlap, but the distribution of 25-hydroxyvitamin $\mathrm{D}(25(\mathrm{OH}) \mathrm{D})$ levels among preterm infants is not known. We aimed to determine the associations between $25(\mathrm{OH}) \mathrm{D}$ levels and gestational age.

METHODS: We measured umbilical cord plasma levels of 25(OH)D from 471 infants born at Brigham and Women's Hospital in Boston. We used generalized estimating equations to determine whether preterm ( $<37$ wks' gestation) or very preterm ( $<32$ wks' gestation) infants had greater odds of having 25(OH)D levels below $20 \mathrm{ng} / \mathrm{ml}$ than more mature infants. We adjusted for potential confounding by season of birth, maternal age, race, marital status, and singleton or multiple gestation.

RESULTS: Mean cord plasma 25(OH)D level was $34.0 \mathrm{ng} / \mathrm{ml}$ (range: 4.1-95.3 and SD: 14.1). Infants born before $32 \mathrm{wks}$ ' gestation had increased odds of having $25(\mathrm{OH}) \mathrm{D}$ levels below $20 \mathrm{ng} /$ $\mathrm{ml}$ in unadjusted (odds ratio (OR): 2.2; 95\% confidence interval (Cl): 1.1-4.3) and adjusted models (OR: 2.4; 95\% Cl: 1.2-5.3) as compared with more mature infants.

CONCLUSION: Infants born in $<32$ wks' gestation are at higher risk than more mature infants for low $25(\mathrm{OH}) \mathrm{D}$ levels. Further investigation of the relationships between low 25(OH)D levels and preterm birth and its sequelae is thus warranted.

P reterm birth is a leading cause of infant mortality and morbidity in the United States, with $12 \%$ of infants born preterm ( $<37$ wks' gestation) (1-3). Risk factors for preterm birth, including African-American race (4), poverty (5), young maternal age (6), and obesity (7), also overlap with risk factors for vitamin D deficiency (8-11). Vitamin D status in the fetus and newborn infant is largely determined by maternal vitamin D status (12). Because maternal vitamin D insufficiency is common (13), it is likely that many newborns are also relatively deficient in 25-hydroxyvitamin $\mathrm{D}(25(\mathrm{OH}) \mathrm{D})$.

Investigators have recently demonstrated an adverse role of low vitamin $\mathrm{D}$ levels on health conditions beyond the traditionally understood calcium metabolism and bone health, such as health status throughout pregnancy (14) and during infancy and childhood (15). Low maternal 25(OH)D concentrations during pregnancy also have been shown to be associated with increased risks of specific conditions, including gestational diabetes (16), preeclampsia (17), and poor fetal growth $(18,19)$. These perinatal complications can precipitate preterm birth, and thus, preterm infants may be at higher risk of vitamin D deficiency. However, the current distribution of $25(\mathrm{OH}) \mathrm{D}$ levels at birth among neonates across the gestational age spectrum is unknown.

To evaluate the association of umbilical cord plasma 25(OH) $\mathrm{D}$ concentrations with gestational age, we analyzed data from a prospective cohort of 471 newborn infants born in Boston (latitude $47.32^{\circ}$ north). We hypothesized that preterm infants would have lower $25(\mathrm{OH}) \mathrm{D}$ levels than their full-term counterparts.

\section{RESULTS}

Mean umbilical cord plasma 25(OH)D level was $34.0 \mathrm{ng} / \mathrm{ml}$ (SD: 14.1; range: 4.1-95.3) (Figure 1). We found that $40.1 \%$ of subjects had 25(OH)D levels below $30 \mathrm{ng} / \mathrm{ml}$, including $14.4 \%$ with levels below $20 \mathrm{ng} / \mathrm{ml}$. We did not detect a clear linear association between $25(\mathrm{OH}) \mathrm{D}$ levels and gestational age (Figure 2).

Infants had lower mean umbilical cord plasma $25(\mathrm{OH}) \mathrm{D}$ levels if they were born in the winter or spring (vs. summer or fall) and if their mothers were black (vs. white), young $(<30$ vs. $\geq 30$ y old), single (vs. married), or insured by Medicaid (vs. private insurance or a health maintenance organization) (Table 1). More of these infants had 25(OH)D levels below $20 \mathrm{ng} / \mathrm{ml}$ as compared with their counterparts (Table 2). Notably, infants born in the winter or spring had $25(\mathrm{OH}) \mathrm{D}$ levels below $20 \mathrm{ng} / \mathrm{ml}$ more than twice as often as infants born in the summer, and black infants had $25(\mathrm{OH}) \mathrm{D}$ levels below $20 \mathrm{ng} / \mathrm{ml}$ six times more often than white infants (39.3 vs. $6.3 \%$, respectively).

Twenty-five percent of infants born before 32 completed wks' gestation had $25(\mathrm{OH}) \mathrm{D}$ levels below $20 \mathrm{ng} / \mathrm{ml}$ vs. $7 \%$ of infants born during 32 to $<37 \mathrm{wks}$ and $14 \%$ of full-term infants (Figure 3). Infants born before $32 \mathrm{wks}$ ' gestation had significantly higher odds of having $25(\mathrm{OH}) \mathrm{D}$ levels below $20 \mathrm{ng} / \mathrm{ml}$ as compared with more mature infants (odds ratio

${ }^{1}$ Harvard Medical School, Boston, Massachusetts; ${ }^{2}$ Department of Neonatology, Beth Israel Deaconess Medical Center, Boston, Massachusetts; ${ }^{3}$ Division of Newborn Medicine, Boston Children's Hospital, Boston, Massachusetts; ${ }^{4}$ Division of Newborn Medicine, Brigham and Women's Hospital, Boston, Massachusetts; ${ }^{5}$ Department of Obstetrics and Gynecology, Brigham and Women's Hospital, Boston, Massachusetts; ${ }^{6}$ Institute of Public Health, University of Heidelberg, Heidelberg, Germany; ${ }^{7} \mathrm{Channing}$ Laboratory, Brigham and Women's Hospital, Boston, Massachusetts; ${ }^{8}$ Division of Pulmonology and Critical Care Medicine, Brigham and Women's Hospital, Boston, Massachusetts. Correspondence: Helen Christou (hchristou@partners.org) 
(OR): 2.2; 95\% confidence interval (CI): 1.1-4.3). This association persisted after adjustment for season of birth, singleton vs. multiple gestation, maternal race/ethnicity, age, and marital status (adjusted OR: 2.4; 95\% CI: 1.2-5.1). Additional adjustment for year of study (2004-2005 vs. 2010-2012), insurance status, and infant sex did not alter these results, and thus, these covariates were omitted from the final, most parsimonious model.

When we analyzed cord blood $25(\mathrm{OH}) \mathrm{D}$ levels in preterm infants by indication for preterm delivery, we found no statistically significant differences among preterm infants born due to maternal preeclampsia, chorioamnionitis, premature rupture of membranes, or preterm labor (Table 3). Similarly, we found no statistically significant differences between cord blood 25(OH)D levels of small-for-gestational-age infants and appropriate-for-gestational-age infants in the overall cohort (data not shown) as well as in the preterm subset (Table 3 ).

Because maternal BMI data were available for only a subset (134/471) of infants, we performed secondary analyses to evaluate whether adjustment for BMI might affect our findings. Mean 25(OH)D levels were highest among infants born to lean women $(38.9 \mathrm{ng} / \mathrm{ml}$; SD: 16.2$)$ as compared with infants born to overweight $(31.6 \mathrm{ng} / \mathrm{ml}$; SD: 15.9$)$ and obese women (32.3 ng/ml, SD: 10.7) $(P=0.03)$. Gestational age was not associated with BMI in this cohort. Among lean, overweight, and

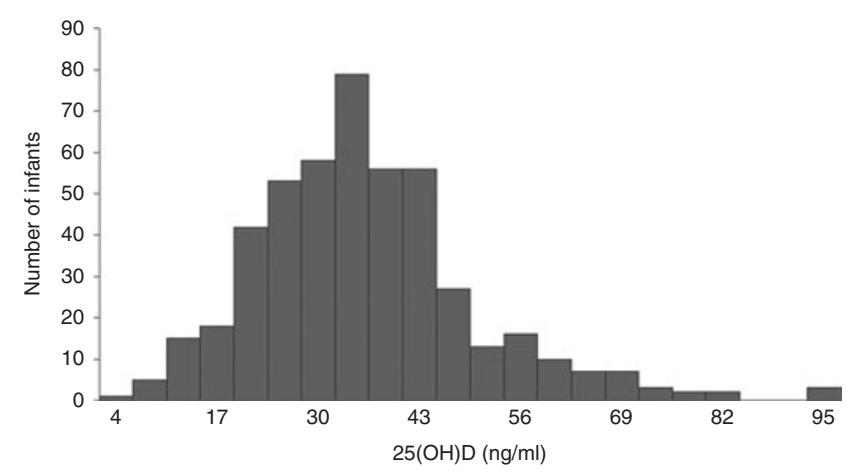

Figure 1. Distribution of umbilical cord plasma 25-hydroxyvitamin $D$ (25(OH)D) levels from 471 infants at Brigham and Women's Hospital, Boston, MA. Mean 25(OH)D: $34.0 \mathrm{ng} / \mathrm{ml}$; SD: 14.1 . Histogram created by assigning values into 22 bins between the minimum value of 4 to maximum value of $95 \mathrm{ng} / \mathrm{ml}$.

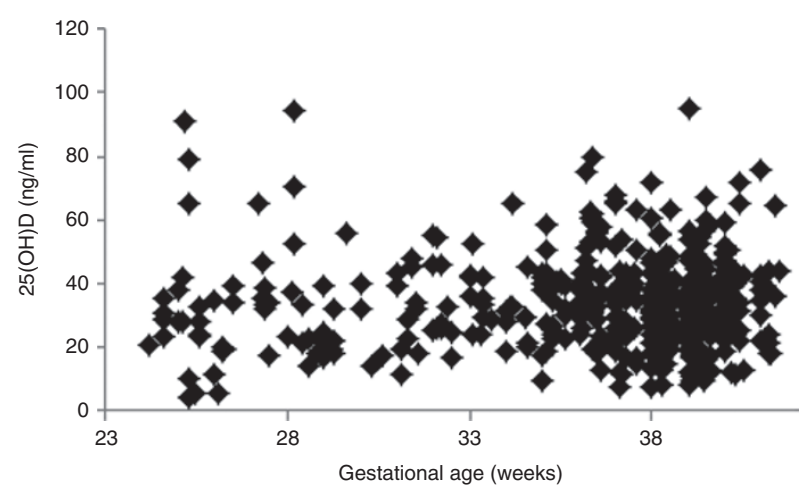

Figure 2. Umbilical cord plasma 25-hydroxyvitamin $\mathrm{D}(25(\mathrm{OH}) \mathrm{D})$ levels from infants of gestational ages $24-41 \mathrm{wk}, n=471 ; r=0.03, P=0.4$. obese women, mean gestational ages were 36.2 (SD: 3.4), 36.8 (SD: 4.7), and 37.0 (SD: 3.9) wk, respectively $(P=0.6)$.

An analogous, adjusted model from the primary analysis in this subset revealed that infants born before 32 wks' gestation had similar odds of having 25(OH)D levels below $20 \mathrm{ng} / \mathrm{ml}$ before and after additional adjustment for maternal BMI (OR: 1.5; 95\% CI: 0.3-7.9 and OR: 1.5; 95\% CI: 0.3-7.8, respectively).

We analyzed cord blood plasma from infants born in two distinct time periods: 59 infants from 2004 to 2005 and 412 infants from 2010 to 2012 . We chose to include the earlier sample because it was enriched for extremely preterm infants. Eight of the 35 infants born before 28 wks' gestation came from this time period. Because of potential influences of prolonged storage on the $25(\mathrm{OH}) \mathrm{D}$ levels from the earlier time period and secular trends in clinical and nutritional practices between the two time periods, we performed a secondary analysis to evaluate the effect of time period. Although we observed a trend in the direction of lower $25(\mathrm{OH}) \mathrm{D}$ levels in the earlier cohort, when we performed the same analysis (final adjusted model) on the later time period alone, we found that our results were not different than when the cohorts were combined: infants in the later cohort born before 32 wks' gestation had increased odds of having 25(OH)D levels $<20 \mathrm{ng} / \mathrm{ml}$ (OR: 2.4; 95\% CI: 1.0-5.9). Further adjustment for time period on our final combined cohort model had no impact on the final adjusted estimate (OR: 2.5; 95\% CI: 1.2-5.3).

\section{DISCUSSION}

We found that, compared with more mature infants, those born before 32 wks' gestation had higher odds of having umbilical cord plasma $25(\mathrm{OH}) \mathrm{D}$ levels below $20 \mathrm{ng} / \mathrm{ml}$. This population of preterm infants suffers from multiple morbidities, including not only metabolic bone disease (20), which is directly related to the well-known physiological effects of vitamin $\mathrm{D}$ and calcium metabolism, but also respiratory sequelae and immune system dysfunction, which also might relate to vitamin D status $(21,22)$. Our study describes the distribution of umbilical cord plasma $25(\mathrm{OH}) \mathrm{D}$ levels at birth across the gestational age spectrum and also highlights the high risk of low $25(\mathrm{OH}) \mathrm{D}$ levels among very preterm infants. Whether such low levels contribute to any of the morbidities of preterm birth remains unknown and should be evaluated in future studies.

In our cross-sectional analyses, we were unable to address whether suboptimal maternal vitamin D status contributed to the preterm births in our cohort. Furthermore, our study is limited by lack of data on prenatal vitamin $\mathrm{D}$ supplementation and maternal 25(OH)D levels and therefore not allowing for better risk prediction of suboptimal vitamin D status. Because umbilical cord plasma $25(\mathrm{OH}) \mathrm{D}$ concentrations are typically within $\sim 90 \%$ of the mother's concentration, and maternal concentrations do not vary significantly throughout pregnancy (12), we do not believe that we are demonstrating a physiological transition at 32 wks' gestation. However, given that fetal and newborn concentrations of $25(\mathrm{OH}) \mathrm{D}$ depend on and correlate with maternal serum levels, vitamin D insufficiency among pregnant women places newborns at a greater risk for vitamin D deficiency (23). 
Table 1. Maternal and infant characteristics and umbilical cord plasma 25(OH)D levels from 471 infants

\begin{tabular}{|c|c|c|c|}
\hline & & $\begin{array}{l}\text { Cord plasma } \\
5(\mathrm{OH}) \mathrm{D}(\mathrm{ng} / \mathrm{ml})\end{array}$ & \\
\hline & 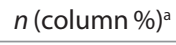 & Mean (SD) & \\
\hline All subjects & $471(100)$ & $34.0(14.2)$ & \\
\hline Characteristics & & & ANOVA $P$ \\
\hline Season of birth & & & $<0.0001$ \\
\hline Spring & $85(18.0)$ & $30.4(11.9)$ & \\
\hline Summer & $152(32.3)$ & $38.3(15.3)$ & \\
\hline Fall & $130(27.6)$ & $36.3(14.5)$ & \\
\hline Winter & $104(22.1)$ & $27.7(10.3)$ & \\
\hline Race/ethnicity & & & $<0.0001$ \\
\hline White & $269(52.7)$ & $37.2(13.6)$ & \\
\hline Black & $61(13.0)$ & $25.3(15.0)$ & \\
\hline Hispanic & $75(15.1)$ & $33.8(12.8)$ & \\
\hline Asian & $54(10.6)$ & $29.9(11.7)$ & \\
\hline Other & $7(1.5)$ & $29.9(13.7)$ & \\
\hline Maternal age (y) & & & $<0.0001$ \\
\hline$<20$ & $13(2.8)$ & $23(7.5)$ & \\
\hline 20 to $<30$ & $115(24.4)$ & $30.0(13.0)$ & \\
\hline 30 to $<40$ & $299(63.5)$ & $35.8(14.0)$ & \\
\hline$\geq 40$ & $41(8.7)$ & $35.5(16.7)$ & \\
\hline Marital status & & & 0.006 \\
\hline Married & $343(72.8)$ & $35.0(14.0)$ & \\
\hline Single & $118(25.1)$ & $30.9(14.4)$ & \\
\hline Insurance status & & & 0.01 \\
\hline Private & $13(2.8)$ & $44.1(19.7)$ & \\
\hline $\mathrm{HMO}$ & $341(72.8)$ & $34.6(14.0)$ & \\
\hline Medicaid & $111(23.6)$ & $31.0(13.6)$ & \\
\hline Self-pay & $3(0.6)$ & $30.7(8.7)$ & \\
\hline Period of birth & & & 0.07 \\
\hline 2004-2005 & $59(12.5)$ & $30.9(13.8)$ & \\
\hline 2010-2012 & $412(87.5)$ & $34.4(14.2)$ & \\
\hline Gestational number & & & 0.07 \\
\hline Singleton & $328(69.6)$ & $33.2(14.4)$ & \\
\hline Multiple & $143(30.4)$ & $35.8(13.5)$ & \\
\hline Infant sex & & & 0.8 \\
\hline Female & $220(46.7)$ & $33.8(14.4)$ & \\
\hline Male & $251(53.3)$ & $34.1(13.9)$ & \\
\hline Gestational age (wk) & & & 0.06 \\
\hline$<32$ & $71(15.1)$ & $31.7(18.1)$ & \\
\hline 32 to $366 / 7$ & $108(22.9)$ & $36.5(13.1)$ & \\
\hline$\geq 37$ & $292(62.0)$ & $33.6(13.3)$ & \\
\hline Maternal BMl $\left(\mathrm{kg} / \mathrm{m}^{2}\right)$ & & & 0.03 \\
\hline$<25$ & $68(50.7)$ & $38.9(16.2)$ & \\
\hline 25 to $<30$ & $40(29.9)$ & $31.6(15.9)$ & \\
\hline$\geq 30$ & $26(19.4)$ & $32.3(10.7)$ & \\
\hline
\end{tabular}

25(OH)D, 25-hydroxyvitamin D; HMO, health maintenance organization.

apercentages may not add up to $100 \%$ due to missing data: maternal race/ethnicity $(n=5)$, maternal age $(n=3)$, insurance $(n=3)$, and marital status $(n=10)$.

${ }^{b}$ Maternal BMI data available for just $28 \%$ of the infants.
Table 2. Categories of umbilical cord plasma 25(OH)D status by maternal and infant characteristics $(n=471)$

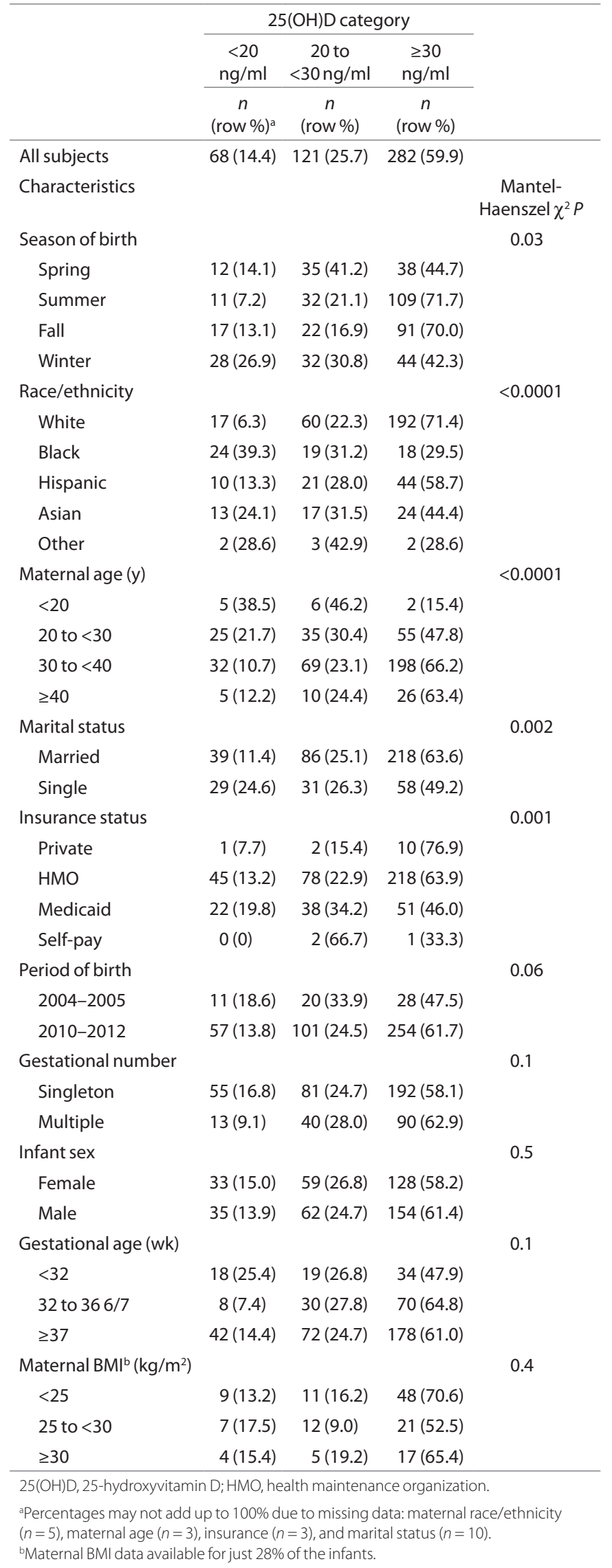




\section{Articles $\mid$ Burrisetal.}

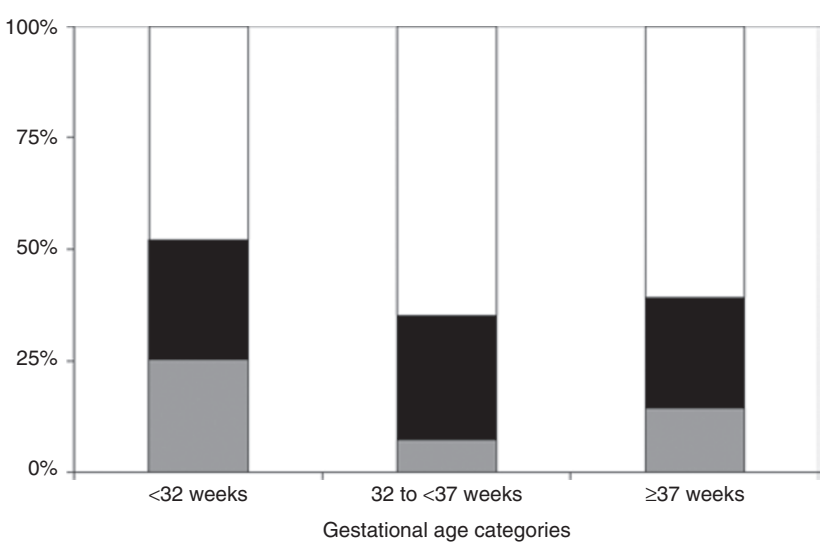

Figure 3. Umbilical cord plasma 25-hydroxyvitamin D (25(OH)D) categories by gestational age group, $n=471$. White bars, $\geq 30 \mathrm{ng} / \mathrm{ml}$; black bars, 20 to $<30 \mathrm{ng} / \mathrm{ml}$; and gray bars, $<20 \mathrm{ng} / \mathrm{ml}$.

Table 3. Pregnancy complications and umbilical cord plasma $25(\mathrm{OH}) \mathrm{D}$ levels among preterm infants

\begin{tabular}{|c|c|c|c|}
\hline & & $\begin{array}{c}\text { Cord plasma } \\
25(\mathrm{OH}) \mathrm{D}(\mathrm{ng} / \mathrm{ml})\end{array}$ & $\begin{array}{l}t \text {-test } \\
P \text { value }\end{array}$ \\
\hline Pregnancy complication & $n$ & Mean (SD) & \\
\hline $\begin{array}{l}\text { Premature rupture of } \\
\text { membranes }\end{array}$ & & & 0.6 \\
\hline Yes & 42 & $33.5(11.6)$ & \\
\hline No & 136 & $35(16.5)$ & \\
\hline Preeclampsia & & & 0.2 \\
\hline Yes & 40 & $32.1(14.4)$ & \\
\hline No & 137 & $35.4(15.8)$ & \\
\hline Preterm labor & & & 0.2 \\
\hline Yes & 78 & $35.9(16.6)$ & \\
\hline No & 90 & $32.8(13.7)$ & \\
\hline Chorioamnionitis & & & 0.08 \\
\hline Yes & 11 & $26.6(9.3)$ & \\
\hline No & 166 & $35.2(15.7)$ & \\
\hline Maternal fever & & & 0.2 \\
\hline Yes & 7 & $27.1(10.2)$ & \\
\hline No & 170 & $35(15.8)$ & \\
\hline Gestational diabetes & & & 0.2 \\
\hline Yes & 15 & $30.5(14.4)$ & \\
\hline No & 145 & $35.1(15)$ & \\
\hline $\begin{array}{l}\text { Small for gestational age } \\
(<10 \text { th percentile) }\end{array}$ & & & 0.98 \\
\hline Yes & 37 & $34.7(11)$ & \\
\hline $\begin{array}{l}\text { No (10th to } \\
\text { 90th percentile) }\end{array}$ & 141 & $34.7(16.4)$ & \\
\hline
\end{tabular}

25(OH)D, 25-hydroxyvitamin D.

Additionally, even infants born to mothers with marginally sufficient 25(OH)D levels still have a risk for 25(OH)D deficiency, whereas those born to mothers with insufficient $25(\mathrm{OH}) \mathrm{D}$ levels are almost certainly deficient themselves (15).
Two recent interventional studies on vitamin D supplementation during pregnancy support a causal relationship between suboptimal vitamin D status and preterm birth $(24,25)$. Hollis et al. (24) reported a trend for decreased duration of gestation in the group of pregnant women receiving lower dose of vitamin D supplementation as compared with the group receiving higher doses of vitamin $\mathrm{D}$ supplementation. The study population differed from our study population in that it did not include multiple gestations or pregnant women with preexisting hypertension or diabetes. Furthermore, there were no infants born at $<36.4$ wks' gestation. A subsequent study by Wagner et al. (25) showed a statistically significant negative association between preterm labor, infection, and preterm delivery with vitamin $\mathrm{D}$ status; however, this finding needs to be confirmed in adequately powered studies. When we analyzed cord $25(\mathrm{OH}) \mathrm{D}$ levels in our preterm infants by indication for preterm birth, we found no statistically significant differences between those with maternal risk factors and those without.

Currently, there is limited information on the distribution of $25(\mathrm{OH}) \mathrm{D}$ levels in preterm infants. A few studies have documented 25(OH)D levels from infants at birth with sample sizes ranging from 8 to 34 infants $(26-30)$ with mean $25(\mathrm{OH})$ $\mathrm{D}$ levels ranging from $16.3 \mathrm{nmol} / \mathrm{ml}(\sim 6.5 \mathrm{ng} / \mathrm{ml})$ among preterm infants born to women in the United Arab Emirates (30) to $29.2 \mathrm{nmol} / \mathrm{l}(\sim 10 \mathrm{ng} / \mathrm{ml})$ in Finland $(27)$. A recent study of 21 full-term infants born to HIV-infected women in Malawi reported mean 25(OH)D levels of $13.8 \mathrm{ng} / \mathrm{ml}$ at birth (31). Our study is the first to describe $25(\mathrm{OH}) \mathrm{D}$ levels across the gestational age spectrum and to demonstrate that, in the absence of a clear linear association between $25(\mathrm{OH}) \mathrm{D}$ levels and gestational age, among the most immature infants, there remains an increased risk of $25(\mathrm{OH}) \mathrm{D}$ levels below $20 \mathrm{ng} / \mathrm{ml}$, a level often cited as deficient by vitamin $\mathrm{D}$ experts (32). Our study has a number of strengths, including a large sample of infants spanning the entire gestational age spectrum and racial/ethnic diversity (only $52 \%$ of infants were born to white mothers). However, in our cohort, adjustment for potential confounders such as BMI and race did not affect our effect estimates. We believe that this is likely due to the particular characteristics of our cohort, in which BMI and race were not associated with preterm birth. Brigham and Women's Hospital serves both urban minority pregnant women seeking routine obstetric care and high-risk suburban (majority white) obstetrical patients. Such referral patterns lead to a higher proportion of white preterm infants than what is seen on a population level. Fifteen percent of white infants and $18 \%$ of black infants in our cohort were born before 32 wks' gestation, and this difference was not statistically significantly different $(P=0.4)$. In the United States, very preterm delivery $(<32 \mathrm{wk})$ is more than twice as common among black infants (3.9\%) compared with white infants (1.6\%) (33).

A limitation of our study was the inability to control for maternal BMI/obesity, a known risk factor for low 25(OH)D levels $(32,34,35)$. On the other hand, we performed secondary analyses on a subset of infants $(n=134)$ for whom maternal 
BMI data were available from the medical record, and adjusting for BMI did not influence effect estimates. Furthermore, there exists, among current researchers, some uncertainty regarding the optimal method of measuring $25(\mathrm{OH}) \mathrm{D}$ levels $(36,37)$. We measured $25(\mathrm{OH}) \mathrm{D}$ using chemiluminescence (38). The laboratory used US National Institute of Standards and Technology level 1 for quality control. Finally, as in all observational studies, it is possible that our results might be affected by other unmeasured confounding variables.

In conclusion, we found that infants born before $32 \mathrm{wks}$ gestation have an increased risk of low 25(OH)D levels (below $20 \mathrm{ng} / \mathrm{ml}$ ) as compared with more mature infants. Whether such low levels contribute to the morbidities that these infants suffer in the neonatal period and beyond warrants further study but may be difficult to detect given the multifactorial etiologies of the sequelae of preterm birth. Interventional trials of vitamin D supplementation among pregnant women at risk of delivering preterm should include infant and childhood follow-up to document benefit to the offspring, if any, of vitamin D supplementation during pregnancy.

\section{METHODS \\ Vitamin D Analysis}

The Institutional Review Board at Brigham and Women's Hospital approved the study, which involved discarded samples and chart review and thus did not require informed consent. We collected umbilical cord blood at the time of delivery from a convenience sample of 471 infants born at Brigham and Women's Hospital, a highrisk tertiary care center in Boston, MA, during the two time periods (2004-2005: 59 samples and 2010-2012: 412 samples). We included the earlier, stored samples from a previous study of preterm infants from the same institution because it was enriched in extremely preterm infants (39). We refrigerated and centrifuged the blood samples and stored plasma aliquots at $-80^{\circ} \mathrm{C}$. We measured the levels of $25(\mathrm{OH}) \mathrm{D}$, a combination of $25(\mathrm{OH}) \mathrm{D}_{2}$ and $25(\mathrm{OH}) \mathrm{D}_{3}$, which represent the best analytes for overall vitamin D status (40), using DiaSorin Liaison (DiaSorin Liaison reagent Integral; DiaSorin, Stillwater, MN) that uses a chemiluminescence immunoassay (38), to determine plasma concentrations of $25(\mathrm{OH}) \mathrm{D}$. For quality control, the laboratory used US National Institute of Standards and Technology level 1. Interassay coefficient of variation was $9.6 \%$. We report $25(\mathrm{OH}) \mathrm{D}$ levels in $\mathrm{ng} / \mathrm{ml}$, which can be multiplied by 2.496 to convert to $\mathrm{nmol} / \mathrm{l}$.

\section{Clinical and Demographic Data Ascertainment}

We calculated gestational age in weeks at the time of birth based on the best obstetrical estimate using the date of last menstrual period with confirming first-trimester ultrasounds. Through medical record reviews, we collected information on potential confounders including maternal race/ethnicity, age, BMI, marital and insurance statuses, and pregnancy complications, including premature rupture of membranes, maternal preeclampsia, preterm labor, chorioamnionitis, maternal fever, and gestational diabetes. We also collected information on season of birth, infant sex and birth weight, and singleton vs. multiple gestations.

\section{Statistical Analyses}

We first performed bivariate analyses to determine maternal and infant characteristics associated with previously described adult clinical categories of vitamin D status $(11,41-43)$ : deficiency $(25(\mathrm{OH}) \mathrm{D}$ level: $<20 \mathrm{ng} / \mathrm{ml})$, insufficiency $(25(\mathrm{OH}) D$ levels: 20 to $<30 \mathrm{ng} / \mathrm{ml})$, and sufficiency $(25(\mathrm{OH}) \mathrm{D}$ level: $\geq 30 \mathrm{ng} / \mathrm{ml})$ as thresholds for analyses. We performed $t$-tests to determine whether $25(\mathrm{OH}) \mathrm{D}$ levels differed by indication for preterm delivery and small-for-gestational-age status. We adjusted for potential confounders (including season of delivery, race/ethnicity, maternal age, insurance and marital statuses, infant sex, and singleton vs. multiple gestation) in multivariable logistic regression models. Maternal prepregnancy BMI data were available for a subset of 134 infants in whom we performed secondary analyses to evaluate the potential impact of BMI on our results. Similarly, we compared results including and then excluding the 59 samples from the earlier time period (2004-2005) to ensure that storage did not affect our findings. We also analyzed these two time periods as potential confounders to ensure that clinical practices that might differ between the two time periods did not explain our findings. To account for clustering by mother among multiples, we used generalized estimating equations (PROC GENMOD). We performed all analyses using SAS 9.2 (SAS Institute, Cary, NC).

\section{ACKNOWLEDGMENTS}

We thank Marcia Filip, Yvonne Sheldon, Elena Arons, and Deirdre Greene for their assistance with cord blood collection and processing and Vanessa Gaines and Elisabeth Annette Scheid for data entry.

\section{STATEMENT OF FINANCIAL SUPPORT}

This work was supported by the Gerber Foundation and the William F. Milton Fund (to H.C.). The project described was supported by the Clinical Translational Science Award UL1RR025758 to Harvard University and Brigham and Women's Hospital from the National Center for Research Resources. A.A.L. and S.T.W. are supported by grant U01 HL091528 (National Heart, Lung and Blood Institute, National Institutes of Health (NIH), Bethesda, MD). H.H.B. was funded by the Klarman Scholars Program at Beth Israel Deaconess Medical Center and by grant K23 ES022242 (National Institute of Environmental Health Sciences, NIH).

This content is solely the responsibility of the authors and does not necessarily represent the official views of the National Center for Research Resources or the $\mathrm{NIH}$.

Disclosure: None declared.

\section{REFERENCES}

1. MacDorman MF, Callaghan WM, Mathews TJ, Hoyert DL, Kochanek KD. Trends in preterm-related infant mortality by race and ethnicity, United States, 1999-2004. Int J Health Serv 2007;37:635-41.

2. Stoll BJ, Hansen NI, Bell EF, et al.; Eunice Kennedy Shriver National Institute of Child Health and Human Development Neonatal Research Network. Neonatal outcomes of extremely preterm infants from the NICHD Neonatal Research Network. Pediatrics 2010;126:443-56.

3. Woythaler MA, McCormick MC, Smith VC. Late preterm infants have worse 24-month neurodevelopmental outcomes than term infants. Pediatrics 2011;127:e622-9.

4. David RJ, Collins JW Jr. Differing birth weight among infants of U.S.born blacks, African-born blacks, and U.S.-born whites. N Engl J Med 1997;337:1209-14.

5. Kramer MS, Séguin L, Lydon J, Goulet L. Socio-economic disparities in pregnancy outcome: why do the poor fare so poorly? Paediatr Perinat Epidemiol 2000;14:194-210.

6. Branum AM, Schoendorf KC. The influence of maternal age on very preterm birth of twins: differential effects by parity. Paediatr Perinat Epidemiol 2005;19:399-404.

7. Djelantik AA, Kunst AE, van der Wal MF, Smit HA, Vrijkotte TG. Contribution of overweight and obesity to the occurrence of adverse pregnancy outcomes in a multi-ethnic cohort: population attributive fractions for Amsterdam. BJOG 2012;119:283-90.

8. Perampalam S, Ganda K, Chow KA, et al. Vitamin D status and its predictive factors in pregnancy in 2 Australian populations. Aust N Z J Obstet Gynaecol 2011;51:353-9.

9. Bodnar LM, Simhan HN. Vitamin D may be a link to black-white disparities in adverse birth outcomes. Obstet Gynecol Surv 2010;65:273-84.

10. Bodnar LM, Catov JM, Roberts JM, Simhan HN. Prepregnancy obesity predicts poor vitamin D status in mothers and their neonates. J Nutr 2007;137:2437-42.

11. Ginde AA, Sullivan AF, Mansbach JM, Camargo CA Jr. Vitamin D insufficiency in pregnant and nonpregnant women of childbearing age in the United States. Am J Obstet Gynecol 2010;202:436.e1-8. 
12. Kovacs CS. Vitamin D in pregnancy and lactation: maternal, fetal, and neonatal outcomes from human and animal studies. Am J Clin Nutr 2008;88:520S-8S.

13. Bodnar LM, Simhan HN, Powers RW, Frank MP, Cooperstein E, Roberts JM. High prevalence of vitamin D insufficiency in black and white pregnant women residing in the northern United States and their neonates. J Nutr 2007;137:447-52.

14. Wagner CL, Taylor SN, Dawodu A, Johnson DD, Hollis BW. Vitamin D and its role during pregnancy in attaining optimal health of mother and fetus. Nutrients 2012;4:208-30.

15. Walker VP, Modlin RL. The vitamin D connection to pediatric infections and immune function. Pediatr Res 2009;65(5 Pt 2):106R-13R.

16. Burris HH, Rifas-Shiman SL, Kleinman K, et al. Vitamin D deficiency in pregnancy and gestational diabetes mellitus. Am J Obstet Gynecol 2012;207:182.e1-8.

17. Bodnar LM, Catov JM, Simhan HN, Holick MF, Powers RW, Roberts JM. Maternal vitamin D deficiency increases the risk of preeclampsia. J Clin Endocrinol Metab 2007;92:3517-22.

18. Burris HH, Rifas-Shiman SL, Camargo CA Jr, et al. Plasma 25-hydroxyvitamin D during pregnancy and small-for-gestational age in black and white infants. Ann Epidemiol 2012;22:581-6.

19. Bodnar LM, Catov JM, Zmuda JM, et al. Maternal serum 25-hydroxyvitamin D concentrations are associated with small-for-gestational age births in white women. J Nutr 2010;140:999-1006.

20. Abrams SA. In utero physiology: role in nutrient delivery and fetal development for calcium, phosphorus, and vitamin D. Am J Clin Nutr 2007;85:604S-7S.

21. Camargo CA Jr, Rifas-Shiman SL, Litonjua AA, et al. Maternal intake of vitamin $\mathrm{D}$ during pregnancy and risk of recurrent wheeze in children at 3 y of age. Am J Clin Nutr 2007;85:788-95.

22. Bodnar LM, Krohn MA, Simhan HN. Maternal vitamin D deficiency is associated with bacterial vaginosis in the first trimester of pregnancy. J Nutr 2009;139:1157-61.

23. Hollis BW, Pittard WB 3rd. Evaluation of the total fetomaternal vitamin $\mathrm{D}$ relationships at term: evidence for racial differences. J Clin Endocrinol Metab 1984;59:652-7.

24. Hollis BW, Johnson D, Hulsey TC, Ebeling M, Wagner CL. Vitamin D supplementation during pregnancy: double-blind, randomized clinical trial of safety and effectiveness. J Bone Miner Res 2011;26:2341-57.

25. Wagner CL, McNeil R, Hamilton SA, et al. A randomized trial of vitamin D supplementation in 2 community health center networks in South Carolina. Am J Obstet Gynecol 2013;208:137.e1-13.

26. Hillman LS, Haddad JG. Human perinatal vitamin D metabolism. I. 25-Hydroxyvitamin D in maternal and cord blood. J Pediatr 1974;84:742-9.

27. Backström MC, Mäki R, Kuusela AL, et al. Randomised controlled trial of vitamin $\mathrm{D}$ supplementation on bone density and biochemical indices in preterm infants. Arch Dis Child Fetal Neonatal Ed 1999;80:F161-6.
28. Delmas PD, Glorieux FH, Delvin EE, Salle BL, Melki I. Perinatal serum bone Gla-protein and vitamin D metabolites in preterm and fullterm neonates. J Clin Endocrinol Metab 1987;65:588-91.

29. Salle BL, Glorieux FH, Delvin EE, David LS, Meunier G. Vitamin D metabolism in preterm infants. Serial serum calcitriol values during the first four days of life. Acta Paediatr Scand 1983;72:203-6.

30. Dawodu A, Nath R. High prevalence of moderately severe vitamin D deficiency in preterm infants. Pediatr Int 2011;53:207-10.

31. Amukele TK, Soko D, Katundu P, et al. Vitamin D levels in Malawian infants from birth to 24 months. Arch Dis Child 2013;98:180-3.

32. Holick MF. Vitamin D deficiency. N Engl J Med 2007;357:266-81.

33. Martin JA, Hamilton BE, Ventura SJ, et al. Births: final data for 2009. Natl Vital Stat Rep 2011;60:1-70.

34. Parikh SJ, Edelman M, Uwaifo GI, et al. The relationship between obesity and serum 1,25-dihydroxy vitamin $\mathrm{D}$ concentrations in healthy adults. J Clin Endocrinol Metab 2004;89:1196-9.

35. Cheng S, Massaro JM, Fox CS, et al. Adiposity, cardiometabolic risk, and vitamin D status: the Framingham Heart Study. Diabetes 2010;59:242-8.

36. Ross AC, Institute of Medicine (U.S.). Committee to Review Dietary Reference Intakes for Vitamin D and Calcium. Dietary reference intakes for calcium and vitamin D. Washington, DC: National Academies Press, 2011.

37. de la Hunty A, Wallace AM, Gibson S, Viljakainen H, Lamberg-Allardt C, Ashwell M. UK Food Standards Agency Workshop Consensus Report: the choice of method for measuring 25-hydroxyvitamin D to estimate vitamin D status for the UK National Diet and Nutrition Survey. Br J Nutr 2010;104:612-9.

38. Ersfeld DL, Rao DS, Body JJ, et al. Analytical and clinical validation of the $25 \mathrm{OH}$ vitamin $\mathrm{D}$ assay for the LIAISON automated analyzer. Clin Biochem 2004;37:867-74.

39. Barnes CM, McElrath TF, Folkman J, Hansen AR. Correlation of 2-methoxyestradiol levels in cord blood and complications of prematurity. Pediatr Res 2010;67:545-50.

40. Zerwekh JE. Blood biomarkers of vitamin D status. Am J Clin Nutr 2008;87:1087S-91S.

41. Bischoff-Ferrari HA, Giovannucci E, Willett WC, Dietrich T, DawsonHughes B. Estimation of optimal serum concentrations of 25-hydroxyvitamin D for multiple health outcomes. Am J Clin Nutr 2006;84:18-28.

42. Holmes VA, Barnes MS, Alexander HD, McFaul P, Wallace JM. Vitamin D deficiency and insufficiency in pregnant women: a longitudinal study. Br J Nutr 2009;102:876-81.

43. van den Ouweland JM, Beijers AM, Demacker PN, van Daal H. Measurement of 25-OH-vitamin D in human serum using liquid chromatography tandem-mass spectrometry with comparison to radioimmunoassay and automated immunoassay. J Chromatogr B Analyt Technol Biomed Life Sci 2010;878:1163-8. 